\title{
A “ABORDAGEM DAS CAPACIDADES" NA TEORIA DE AMARTYA SEN SOBRE O DESENVOLVIMENTO HUMANO
}

\section{THE "CAPACITY APPROACH" IN THE THEORY OF AMARTYA SEN ABOUT HUMAN DEVELOPMENT}

\section{THAIS NOVAES CAVALCANTI}

Doutora em Direito Constitucional e Mestre em Direito do Estado pela Pontifícia Universidade Católica de São Paulo. Possui Master em Teologia pela Pontifícia Università Lateranense de Roma - Itália. Professora do programa de Mestrado em Direitos Fundamentais e Alteridade na Universidade Católica de Salvador. Coordenadora do curso de Direito da Faculdade de Direito de São Bernardo do Campo. Coordenadora do Observatório da Subsidiariedade que estuda a atuação da sociedade civil organizada nos Direitos Fundamentais.

\section{ELISAIDE TREVISAM}

Doutora em Filosofia do Direito pela Pontifícia Universidade Católica de São Paulo. Mestre em Direitos Humanos. Especialista em Direito do Trabalho e Processo do Trabalho. Pesquisadora na área do Direito, com ênfase em Direitos Humanos e Filosofia do Direito. Professora Visitante Nacional no Programa de Mestrado em Direito da Universidade Federal de Mato Grosso do Sul - UFMS.

\section{RESUMO}

A presente pesquisa tem o objetivo de desenvolver uma breve reflexão sobre Amartya Sen e sua teoria da abordagem das capacidades (capabilities approach) para 0 alcance do desenvolvimento humano. Em um primeiro momento, será feita uma breve análise conceitual das capacidades humanas que dará sustentação, em um segundo momento, à abordagem das capacidades como desenvolvimento humano para, por fim, concluir que a abordagem das capacidades humanas constitui uma estratégia de 
desenvolvimento das instituições políticas, da sociedade e do Estado democrático. Para alcançar os objetivos propostos na presente reflexão, a pesquisa será elaborada por meio de uma análise bibliográfica através de um método dedutivo.

PALAVRAS-CHAVE: Amartya Sen; capacidade; capabilities approach; liberdade; desenvolvimento humano.

\section{ABSTRACT}

The present research aims to develop a brief reflection about Amartya Sen and the capabilities approach created by him to reach of human development. At first, a brief conceptual analysis of the human capacities, in a second moment, the capabilities approach used to formed the concept of human development, lastly, to conclude that the human capabilities approach constitutes a strategy for the development of political institutions, society and the democratic State. To reach the objectives proposed in the present reflection, the research will be elaborated through a bibliographical analysis through a deductive method.

KEYWORDS: Amartya Sen; capabilities; capabilities approach; freedom; human development.

\section{INTRODUÇÃO}

O conceito de Desenvolvimento Humano foi construído, em grande parte, pelo pensamento de Amartya Sen ${ }^{1}$ que, baseado na expansão das capacidades das pessoas, pretende aumentar as possibilidades de escolhas como a liberdade de cada um de levar um determinado tipo de vida. Liberdade que cada pessoa tem para

\footnotetext{
${ }^{1}$ Amartya Sen nasceu em Santiniketan, Índia, foi professor na Delhi School of Economics e na London School of Economics, pertenceu ao quadro docente de Harvard University por mais de uma década e, desde 1998, é Reitor do Trinity College (Cambridge University). Em 1998, ganhou o prêmio Nobel de Economia por suas contribuições à economia do bem-estar estabelecendo novos paradigmas para o desenvolvimento e para teoria da escolha social [social choice].
} 
determinar o que quer, o que valoriza e o que decide escolher por ela mesma, pelos outros, pela comunidade onde está inserida e pelo Estado. Maior liberdade significa maior oportunidade para buscar os objetivos individuais.

Buscando desenvolver uma reflexão sobre as implicações sociais e políticas na atual sociedade, o objetivo da presente pesquisa é o de ilustrar como o pensamento de Amartya Sen e a abordagem das capacidades interferem em diversas áreas do conhecimento e para as pesquisas no âmbito do Direito e Desenvolvimento Humano.

Diante disso, e considerando o desenvolvimento humano como uma questão política e social, serão apresentados os argumentos de Amartya Sen no que tange à abordagem das capacidades como fundamentação do desenvolvimento humano e, para tanto, procurar-se-á fazer uma breve conceituação de capacidade e liberdade, passando pelo pensamento aristotélico sobre felicidade para, por fim, alcançar o resultado desejado.

Para alcançar os objetivos aqui propostos, a presente pesquisa se dará por meio de uma análise científica de cunho bibliográfico relacionando conceitos filosóficos e jurídicos através de um método de abordagem dedutivo.

\section{BREVES APORTES SOBRE O CONCEITO DE 'CAPACIDADE’ (CAPABILITIES)}

O conceito de capacidade, de acordo com o dicionário Houaiss (2009, p. 391) da língua portuguesa, significa: "1. potencial para conter, acomodar ou guardar algo; volume; 2. poder de produção, de execução; rendimento máximo; 3. qualidade ou condição de capaz; habilidade física ou mental de um indivíduo, aptidão, perícia". Nesse conceito, é possível perceber que o termo está relacionado tanto a aspectos materiais de quantidade quanto a características imateriais ligadas à pessoa, como habilidade, aptidão.

Interessante destacar que, na língua inglesa, há um desdobramento dessa palavra entre capacity e capability. De acordo com o Dicionário Little Oxford English Dictionary (2006), a palavra capacity indica, como em português, vários significados: "1. The maximum amount that something can contain or produce; 2 . The ability or 
power to do something; 3. A role or position". No entanto, a palavra capability é mais específica para um aspecto relacionado à pessoa, como indica o mesmo dicionário: "capability - the power or ability to do something".

Disso é possível verificar que 'capacidade', para os fins deste estudo, tem sua origem na palavra 'capability' do inglês, mais específica do que a palavra 'capacity'. O mesmo sentido é dado por Amartya Sen quando desenvolve a 'abordagem das capacidades', do inglês "capabilities approach", em seus escritos e livros. Esse estudo parte, então, do conceito inicial de capacidade como "o poder ou habilidade de fazer algo" (capability).

Contudo, é justamente no âmbito da Filosofia que a palavra adquire conteúdo amplo e complexo, como "termo alternativo para a potencialidade das coisas (ver ato e potência)", e, já nessa segunda referência, "oposição entre o que é de fato, ou realmente, o caso, e o que poderia ter sido ou pode vir a ser o caso". Portanto, na Filosofia, a capacidade está relacionada à potencialidade, ou seja, à realização da potência em ato. (BLACKBURN, 1997)

Na Metafísica, Aristóteles explica, em breve síntese, que ato e potência são conceitos ontológicos desenvolvidos para explicar o fenômeno da mudança. Dynamis (grego) ou actus (latim) é a "faculdade de produzir movimento ou mudança; em sentido amplo, é possibilidade ontológica". Já "energeia (grego) ou potentia (latim) é um predicado de fato ou segundo a realidade". (BLACKBURN, 1997)

Aristóteles faz uma diferenciação entre potência ativa e potência passiva, sendo uma a possibilidade de fazer e a outra a possibilidade de ser modificada. Para ele, a possibilidade de fazer (potência ativa) pode ser identificada com o termo capacidade. Existem dois tipos de capacidades: a-racionais ou irracionais e racionais. As capacidades irracionais são inatas, faculdades naturais, produzem efeitos necessários, em apenas uma direção. Por exemplo: ouvir, enxergar. Já as capacidades racionais são adquiridas, são aprendidas por exercício e permitem possibilidades alternativas, fazer ou não fazer. Por exemplo: a medicina, que pode curar e provocar doenças; a música, o esporte. A não existência das capacidades irracionais pode ser denominada de privação, enquanto as capacidades racionais (adquiridas) podem ou não existir, tornando-se habitus e até mesmo virtudes. (BLACKBURN, 1997) 
A ciência jurídica também conceitua o termo 'capacidade', destacando essa distinção entre faculdades inatas e possibilidades adquiridas. Ao tratar do tema, a Enciclopédia Saraiva de Direito distingue três formas de capacidade: física, psicológica e jurídica, constituindo "a capacidade física e psicológica suporte da capacidade jurídica, que é o conceito derivado". "No que diz respeito às pessoas físicas - personalidade, sujeito -, coexistem a capacidade física, a de atuar no plano material, e a capacidade psicológica, a de ser criador e parte do processo de convivência", (ENCICLOPÉDIA SARAIVA DE DIREITO, 1977, p. 564-565). Portanto, nessa linha de raciocínio, capacidade jurídica compreende tanto aspectos de personalidade quanto aspectos do agir humano, em resumo considera-se a "aptidão de determinada coisa ou pessoa para atender a uma finalidade pretendida". (DINIZ, 2005)

$\mathrm{Na}$ linguagem jurídica, o termo capacidade adquire diversas conotações, dependendo da área do direito que está sendo utilizada (capacidade civil, capacidade ao exercício da empresa, capacidade de direito público, capacidade processual). Tanto é assim que a Enciclopedia del diritto (1960) apresenta um estudo minucioso e dedica 182 páginas para tratar do termo capacità e de seus desdobramentos dentro da ciência jurídica.

Em sua parte introdutória, há um estudo importante sobre a noção técnicojurídica de capacità, explicando que o termo pode ser dividido em dois principais conceitos: capacidade jurídica (capacità giuridica) e capacidade de agir (capacità di agire). Para o autor do verbete, ambas denotam "una idea comune, idea di comprensione o di continenza che è suggerita del resto dall'etimologia della parola: capacità viene da 'capax' - che contine - e da 'capere' - prendere, comprendere, contenere". (ENCICLOPEDIA DEL DIRITTO,1960, p. 9) ${ }^{2}$

A expressão capacidade jurídica está ligada à ideia de sistema jurídico e ao fato de que todo direito corresponde a um sujeito, necessariamente. Essa ideia está associada ao princípio da igualdade, em que

\footnotetext{
2 "Uma ideia comum, ideia de compreensão ou de abstração, que é sugerida pela etimologia da palavra: capacidade vem de 'capax' - que contêm - e de 'capere' - prender, compreender, conter". (Tradução livre dos autores).
} 
[...] il soggetto físico è considerato, in astratto, punto di collegamento di tutte le norme del sistema: nessun campo di diritti e di obbligui gli è precluso in antecipo per la mancanza di qualità costanti o status. La símplice qualità umana è dunque suficiente a rendere il soggetto portatore potenziale di tutti gli interessi giuridici tutelati dal sistema, nonchè titolare di un insieme di diritti e di garanzie che si collegano imediatamente ala sua personalità. (ENCICLOPEDIA DEL DIRITTO,1960 p. 12) ${ }^{3}$

Em contrapartida, a capacidade de agir denota um diverso momento da subjetividade jurídica, "capace di agire è il soggetto per la possibilità che il diritto gli riconsce, di rivelare nel mondo giuridico e fare in esso valere interessi: perchè dunque, è in grado di determinare, con i propri comportamenti, l'applicazione dele norme e l'insorgere degli effetti da esse predisposte". (ENCICLOPEDIA DEL DIRITTO,1960, p. $16)^{4}$

Em resumo, para a teoria do direito, o termo capacidade implica em a pessoa ser sujeito de direitos pelas atribuições da personalidade, estando apta para agir dentro das normas que o ordenamento jurídico reconhece, produzindo efeitos e responsabilidades. Ambos os aspectos expostos acima partem da ideia de atributos da pessoa, ou seja, de um "ente com personalidade", do qual decorrem o nome, o domicílio, a fama, o status (individual, familiar e social) e a capacidade. ${ }^{5}$

Importante esclarecer que esse conceito apresentado difere daquele dos direitos da personalidade, que, apesar de ser comumente utilizado para tratar da pessoa como ente com personalidade, pode também referir-se a "determinada teoria jurídica elaborada que se compraz em cuidar de certas situações jurídicas especialíssimas, que têm por objeto bens que compõem a natureza humana (ou seja, a humanidade do ser)". Ao direito de personalidade entendido dessa maneira, alguns

\footnotetext{
3 "O sujeito físico é considerado, em abstrato, ponto de ligação de todas as normas do sistema: nenhum campo dos direitos e das obrigações o é precluso em antecipação pela falta de qualidade constante ou status. A simples qualidade humana é suficiente para tornar o sujeito potencial portador de todos os interesses jurídicos tutelados pelo sistema, ou seja, titular de todos os direitos e garantias que se ligam imediatamente a sua personalidade". (Tradução livre dos autores).

4 "Capaz de agir é o sujeito pela possibilidade que o direito o reconhece, de revelar no mundo jurídico e fazer neste mesmo valer seus interesses: porque é em grau de determinar, com os próprios comportamentos, a aplicação das normas e o surgimento dos efeitos por ela gerados" (Tradução livre dos autores). E completa: "La capacità di agire concerne appunto questa possibilità del soggetto, di pore in essere fatti giuridici e provocare la costituzione di effetti giuridici, di rivelare interessi pratici previsti dal diritto o incidere su di essi, mettendo in moto il meccanismi con cui la legge garantisce la loro tutela".

${ }^{5}$ Código Civil Brasileiro, artigos 1ำ ao 10.
} 
autores sugerem o nome de "direito de humanidade". (NERY JUNIOR; NERY, 2009, p. 223)

Outra concepção é dada ao termo "capacidade" por Amartya Sen (1979, p. 218), ao tratar do desenvolvimento humano e da teoria da economia do bem-estar. Ele propõe o 'enfoque das capacidades' (capabilities approach) para a avaliação dos índices de desenvolvimento humano dos países em todo o mundo.

Faz-se importante destacar que o pensamento de Sen significou uma mudança de paradigma para o pensamento econômico pois, colocou a 'expansão das capacidades humanas' como ponto central das políticas públicas do Estado em busca do cumprimento dos direitos fundamentais e da democracia. A escolha e a valoração das capacidades relevantes devem ser feitas pelos próprios envolvidos em um processo aberto de caráter racional e democrático, identificado como causa do desenvolvimento socioeconômico e como expansão das capacidades. (SEN, 2000, p. 173)

Acrescentando que o importante é "reconhecer as capacidades e os direitos humanos como proposições morais capazes de servir de base para a legislação" (SEN, 2011, p. 398), resolveu, desta forma, o problema normativo, colocando que o novo paradigma está no fato de que as pessoas devem ser consideradas em primeiro lugar, em suas capacidades, para se alcançar a justiça formal e material.

Para uma melhor compreensão do termo capacidade segundo as reflexões de Amartya Sen, é imprescindível que se aborde o conceito de Capabilities Approach como principal destaque do processo de desenvolvimento.

\section{A 'ABORDAGEM DAS CAPACIDADES' [CAPABILITIES APPROACH] NA TEORIA DE AMARTYA SEN}

O conceito de abordagem das capacidades (capabilities approach) foi apresentado por Amartya Sen pela primeira vez em maio de 1979, em sua conferência denominada “Equality of What?", proferida em Standford University: "It is arguable that 
what is missing in all this frameworks is some notion of 'basic capabilities': a person being able to do certain basic things". ${ }^{6}$

Nesse texto, a pergunta básica colocada por Sen é "o que deve ser igualado" em uma sociedade, nas políticas apresentadas pelo Estado, na vida das pessoas, para que haja maior igualdade e desenvolvimento? A resposta preliminar dada por ele foi: "as capacidades é que devem ser igualadas" (SEN, 2008, p. 12). Mas, o que são essas capacidades?

No livro Desigualdade reexaminada (2008, p. 13), Sen explica que "a perspectiva da capacidade é uma concepção da igualdade de oportunidades, que destaca a liberdade substantiva da qual as pessoas são portadoras para levar suas vidas. Essa liberdade denota o que as pessoas podem fazer ou realizar, quer dizer, a liberdade para buscar seus objetivos. As 'oportunidades reais' (ou substantivas) de que uma pessoa dispõe para realizar, entre outras coisas, objetivos ligados ao bemestar (well-being objective) são representadas por sua 'capacidade' (capability)".

Utilizando as palavras de Sen, a abordagem das capacidades "concebe a vida humana como um conjunto de 'atividades' e de 'modos de ser' que poderemos denominar 'funcionamentos' (functionings) - e relaciona o julgamento sobre a qualidade da vida à avaliação da capacidade de funcionar ou de desempenhar funções" (SEN, 1985, p. 43). Deixando claro que a noção básica dessa abordagem é a de 'funcionamentos', concebidos como elementos constitutivos da vida, Sen (1985, p. 44) explica:

Um 'funcionamento' é uma conquista de uma pessoa: é o que ela consegue fazer ou ser e qualquer desses funcionamentos reflete, por assim dizer, uma parte do estado da pessoa. A capacidade de uma pessoa é uma noção derivada. Ela reflete as várias combinações de funcionamentos (atividades e modos de ser) que uma pessoa pode alcançar.

Para ajudar na compreensão do conceito, pode-se citar um exemplo dado por Sen que ilustra a natureza de um funcionamento (functioning):

\footnotetext{
6 "É passível de argumentação que o que está faltando em todas essas molduras seja uma noção de 'capacidades básicas': uma pessoa sendo capaz de fazer certas coisas básicas". (Tradução livre dos autores). Ver também Commodities and Capabilities. Nova Delhi: Oxford University Press, 1985; The standard of living. org. G. Hawthorne, Cambridge University Press, 1987; Desenvolvimento como liberdade. São Paulo: Companhia das Letras, 2000 e La calidad de vida, México: FCE, 1996.
} 


\begin{abstract}
A bicicleta possui 'características', tais como transportar quem a pedala. Posso ter uma bicicleta ou não. Posso apenas estar perto de uma. Posso apenas achá-la um objeto bonito. Posso me sentir bem vendo pessoas andando de bicicleta. Mas também posso fazer uso daquela característica da bicicleta, por exemplo. E de diferentes maneiras. Posso me exercitar andando numa todas as manhãs. Posso usá-la como meio de transporte de casa para o trabalho. Algumas vezes, isso me é prazeroso. Mas outras, embora chegando em casa mais rapidamente, não sinto prazer tendo que pedalar depois do trabalho. Deslocar-se, dar um passeio, transportar-se, ir ao trabalho, trabalhar (como um ciclista profissional, ou como um motorista de bici-taxi) e pedalar são todas atividades e realizações que uma pessoa pode alcançar usando uma bicicleta. Todas elas são funcionamentos. Funcionamentos são definidos como estados e ações que uma pessoa consegue realizar vivendo de algum modo. (SEN, 2008, p. 15).
\end{abstract}

Em suma:

[...] a capacidade de uma pessoa se refere às combinações alternativas de funcionamentos, entre cada uma das quais (isto é, de combinações) uma pessoa pode escolher a que terá. A capacidade de uma pessoa corresponde à liberdade que tem para levar um determinado tipo de vida. O enfoque está baseado em uma visão da vida como combinações de várias 'atividades' e 'modos de ser', nos quais a qualidade de vida deve avaliar-se em termos de capacidade para conseguir funcionamentos valiosos (importantes). (NUSSBAUM; SEN, 1996, p. 18)

De acordo com Sabina Alkire (2008, p. 5) ${ }^{7}$, esses funcionamentos são também finalidades da vida humana, podem ser significados da vida humana. Por isso mesmo, os funcionamentos "can be elementary (escaping morbidity and mortality; nourishment; mobility), can be complex (self-respect, participation in community life, ability to appear in public without shame), can be general (capability to be nourished), can be specific (capability to drink 7up)".

Assim, o ponto fundamental dessa concepção de capacidade é a sua intrínseca relação com a liberdade, ou seja, com a possibilidade de transformar capacidades naturais (potências) e hábitos para alcançar um determinado fim (ato). Esse é o principal contraste com as abordagens de utilidade e recursos propostas pelas teorias econômicas convencionais, que consideram benefícios de vantagem ao invés de realização da pessoa. Conforme afirma Amartya Sen (2011, p. 266), o foco é:

\footnotetext{
7 "Podem ser elementares (não ter doenças e fugir da morte; nutrição, acessibilidade), podem ser complexos (autorrespeito, participação na vida da comunidade, habilidade de aparecer em público sem ter vergonha), podem ser gerais (capacidade de estar nutrido) ou podem ainda ser específicos (capacidade de beber uma 7up)" (Tradução livre dos autores).
} 
[...] a liberdade que uma pessoa realmente tem para fazer isso ou ser aquilo - coisas que ela pode valorizar fazer ou ser. A ideia de liberdade também diz respeito a sermos livres para determinar o que queremos, o que valorizamos e, em última instância, o que decidimos escolher. O conceito de capacidade está, portanto, ligado intimamente com o aspecto de oportunidade da liberdade, visto com relação a oportunidades 'abrangentes', e não apenas se concentrando no que acontece na 'culminação' dessa liberdade.

A liberdade para Sen (2000, p. 31-32) tem dois principais aspectos, que ele denomina de "aspecto de processo" e "aspecto de oportunidade". O primeiro está ligado aos processos do dia a dia, da própria vida, ou seja, a liberdade de alterar os 'caminhos' da vida, as escolhas. Já o segundo diz respeito à escolha em si, à liberdade de melhorar a si próprio. Processo e oportunidade são dois aspectos da ideia de liberdade. Esse foco na liberdade desloca a análise dos meios de vida para as oportunidades reais de vida, o interesse é a oportunidade de satisfazer os fins e a liberdade substantiva para realizar os fins desejados.

Assim, a abordagem das capacidades atribui importância à "aptidão para decidir viver como gostaríamos e para promover os fins que quisermos fazer avançar" e também "ao próprio processo de escolha" (SEN, 2011, p. 262), ou seja, à liberdade substantiva. Por isso mesmo, Sen optou por definir o desenvolvimento como liberdade, em seu livro com o mesmo nome, e não como capacidade, pois, para ele, a liberdade é a faculdade (ou direito) que dá origem e sentido à capacidade.

Nesse contexto, a promoção das capacidades refere-se intrinsecamente ao conceito de liberdade, ao agir humano. Sendo assim, pode-se sustentar que o desenvolvimento de um país se mede por "como" a liberdade das pessoas é valorizada e proporcionada. Assim, tanto as leis como o Estado devem ser determinados para promover a liberdade de ser e de escolher, para promover as capacidades das pessoas.

A proposta de Sen é de que a qualidade de vida, o bem-estar das pessoas não pode ser medido apenas pelos bens materiais que possuem e que the são garantidos, mas também e principalmente pela possibilidade que lhe é dada de expandir suas capacidades.

Além disso, Sen propõe a compreensão de duas distinções conceituais importantes para poder avaliar se a 'abordagem das capacidades' é um bom guia para 
o bem-estar: (1) o contraste entre agência e bem-estar; (2) a distinção entre liberdade e realizações. Com relação ao primeiro ponto, de acordo com o próprio autor, "a agência como um todo abrange todos os objetivos que uma pessoa tem razão para adotar, que podem incluir, inter alia, outros fins que não o avanço de seu próprio bemestar. A agência pode assim gerar ordenações de preferência diferentes daquelas geradas pelo bem-estar". Normalmente, bem-estar e agência tem algo em comum, mas isso não os transforma em conceitos congruentes. Já a segunda distinção é mais simples, refere-se à realização em si do ato e a liberdade para realizar (algo anterior). (SEN, 2011, p. 321)

Essas distinções descritas acima produzem quatro diferentes conceitos de vantagem em relação a uma pessoa, que são utilizadas como um exercício avaliativo, segundo Sen (2011, p. 322) ${ }^{8}$, inclusive no contexto da elaboração da política estatal, a saber: "(1) 'realização do bem-estar'; (2) 'realização da agência'; (3) 'liberdade para o bem-estar'; (4) 'liberdade da agência'".

$\mathrm{Na}$ teoria econômica do bem-estar e desenvolvimento, a 'abordagem das capacidades', tal como desenvolvida por Amartya Sen, é a base informacional, ou seja, compõe o total de informações que a teoria utiliza para suas análises. Sua proposta é poder medir e avaliar o desenvolvimento de um país e o bem-estar (qualidade de vida) das pessoas, de acordo com a expansão das capacidades. Daí a proposta de 'funcionamento' e também o fundamento na liberdade.

Por tratar essencialmente da liberdade, Sen (1985) destaca a 'condição do agente' (agency aspect) como outro aspecto fundamental. Este nada mais é do que a valorização da pessoa que age e ocasiona mudança e cujas realizações podem ser julgadas de acordo com seus próprios valores e objetivos, independentemente de as avaliarmos ou não também segundo algum critério externo. A condição de agente, como algo próprio da pessoa, atuando como membro do público e como participante de ações econômicas, sociais e políticas, interagindo no mercado e até mesmo

\footnotetext{
8 "Por exemplo, o Estado pode ter razão para oferecer a uma pessoa oportunidades adequadas para superar a fome, mas não para insistir em que ela precisa aceitar sem falta a oferta. A oferta a todos da oportunidade de levar uma vida minimamente decente não necessita ser unida à insistência de que todos façam uso de todas as oportunidades que o Estado oferece. Por exemplo, a garantia a todos do direito de dispor de uma quantidade adequada de alimento não necessita ser unida a uma proibição estatal do jejum".
} 
envolvendo-se, direta e indiretamente, em atividades individuais ou conjuntas na esfera política ou em outras esferas.

Para Sabina Alkire (2008), são quatro os principais conceitos (cor concepts) úteis para compreender o pensamento de Amartya Sen: a) 'funcionamentos'; b) Liberdade; c) Pluralismo e d) Incompletude. Todos estão relacionados especificamente à abordagem das capacidades. Os dois últimos conceitos: pluralismo e incompletude, são os aspectos mais criticados da teoria de Amartya Sen, pois, apesar de ter firmado as bases de um novo paradigma de desenvolvimento, ele não fixou uma lista de capacidades básicas, de necessidades básicas ou liberdades básicas. Porém, é importante ressaltar que ele o fez propositalmente.

Segundo o autor, deixá-las em aberto (incompletude) compõe o próprio conceito de liberdade de cada indivíduo, considerando que cada Estado e cada sociedade deverão, por meio de um processo democrático e do princípio da subsidiariedade, definir quais são as capacidades a serem expandidas.

\section{DESENVOLVIMENTO DAS CAPACIDADES COMO ESTRATÉGIA PARA O DESENVOLVIMENTO HUMANO}

A teoria econômica de Amartya Sen é bastante complexa e ampla e não será abordada em sua totalidade neste artigo, apenas foram utilizados conceitos fundamentais para a compreensão ampla do termo 'capacidade'. A abordagem das capacidades, por ele desenvolvida, fornece diretrizes importantes para a concretização da promoção das capacidades por parte do Estado.

Amartya Sen influenciou a formulação do IDH - Índice de Desenvolvimento Humano -, utilizado pela ONU para avaliar e medir as políticas de desenvolvimento dos países. Anualmente, são elaborados relatórios de desenvolvimento humano $(\mathrm{RDH})$, que, inclusive, servem de base para políticas internas e internacionais de investimento e financiamento.

Na base da sua investigação está a 'abordagem das capacidades' (capabilties approach), crítica direta ao pensamento utilitarista incorporado às teorias da New Welfare Economics do início do século XX, cujo principal autor foi Keneth Arrow (SEN, 
Amartya; WILLIANS, B., 1982, p. 4-5) ${ }^{9}$. Com referência ao aspecto filosófico, a teoria de Amartya Sen apresenta um aprofundamento crítico à Teoria da Justiça formulada por John Rawls (1997), que, em síntese, parte da "ideia fundamental de que justiça tem de ser vista com relação às exigências da equidade". Em seu livro, $A$ ideia de Justiça (2011), Amartya Sen faz dedicatória "À memória de John Rawls" e delineia seu pensamento partindo da base filosófica e política de Rawls, com admiração e respeito. No entanto, deixa claro, no final do capítulo denominado "Rawls e mais além", que sua teoria tende a abordar aspectos não finalizados pelo pensamento de Rawls:

\begin{abstract}
A análise de Rawls da equidade, da justiça, das instituições e do comportamento iluminou profundamente nosso entendimento de justiça e desempenhou - e ainda desempenha - um papel extremamente construtivo no desenvolvimento da teoria da justiça. Mas não podemos fazer do modo rawlsiano de pensar a justiça uma 'parada' intelectual. Temos de nos beneficiar da riqueza das ideias de Rawls - e depois seguir em frente, em vez de tirar 'férias'. Necessitamos de 'justitia', não de 'justitium'. (SEN, 2011, p. 104).
\end{abstract}

De acordo com Mahbud ul Haq, criador, com Amartya Sen, do IDH, o objetivo dos RDHs é "alterar o foco da economia do desenvolvimento da contabilidade da renda nacional para políticas centradas em pessoas" (HAQ, 1995). E completa, "the real wealth of a nation is its people. And the purpose of development is to create an enabling environment for people to enjoy long, healthy and creative lives. This simple but powerful truth is too often forgothen in the persuit of material and financial wealth". 10

A partir da união entre aspectos da teoria econômica e da filosofia social, Sen preocupou-se em avaliar a qualidade de vida das pessoas em seus países, evidenciando que o crescimento econômico (riquezas) não seria suficiente para tanto, assim como a tradicional medida do PIB - Produto Interno Bruto - de um país não seria suficiente para medir o desenvolvimento. Em suma, "lo scopo sia dello sviluppo

\footnotetext{
${ }^{9}$ Ver também dissertação de mestrado em economia política: $O$ debate de Amartya Sen com Kenneth Arrow e John Rawls e a abordagem das capacidades, de Bruno Beltrame, PUC-SP, 2009.

${ }^{10}$ UNDP, Reports, 1990. "A real riqueza de uma nação é seu povo. E o objetivo do desenvolvimento é criar um meio ambiente que permita às pessoas usufruir uma vida longa, saudável e criativa. Esta simples mas poderosa verdade é muitas vezes esquecida na busca pela riqueza material e financeira" (Mahbud UI Haq). (Tradução livre dos autores).
} 
umano sia dei progetti di riduzione dele povertà deve essere quello di espandere la capacità delle persone di godere di tutto ciò che, per esse, ha valore" (BOMPIANI, 2006, pp. 1618-1619) ${ }^{11}$. Essas ideias foram traduzidas no Relatório de Desenvolvimento Humano de 2011 (RDH 2011), elaborado pela UNDP (United Nations Development Program) da seguinte forma:

O desenvolvimento humano consiste no alargamento das liberdades e capacidades das pessoas para viverem vidas que valorizam e que têm motivos para valorizar. Trata-se de alargar as escolhas. As liberdades e capacidades constituem uma noção mais alargada do que a de necessidades básicas.

Para Amartya Sen, o conceito de desenvolvimento é expansão das capacidades das pessoas, mais do que simplesmente aumentar ou igualar as oportunidades auferidas, para que sejam mais livres (liberdade substancial) para viver a vida escolhida por elas mesmas. Há uma via de mão dupla, em que as capacidades das pessoas são valorizadas e aumentadas pelas políticas públicas do Estado por um lado, e de outro as políticas públicas são influenciadas pelo uso efetivo das capacidades participativas das pessoas.

Sen se afasta dos pressupostos da economia e alia a justiça com a teoria do desenvolvimento. Enquanto a ética está relacionada à economia, para Sen aquilo que é justo está relacionado ao desenvolvimento humano. Consequentemente, pode-se medir o grau de desenvolvimento de uma sociedade pelas liberdades substantivas que os membros dessa sociedade detêm:

As liberdades não são apenas os fins primordiais do desenvolvimento, mas também os meios principais. Além de reconhecer, fundamentalmente, a importância avaliatória da liberdade, precisamos entender a notável relação empírica que vincula, umas às outras. Liberdades políticas (na forma de liberdade de expressão e eleições livres) ajudam a promover a segurança econômica. Oportunidades sociais [...] facilitam a participação econômica. Facilidades econômicas [...] podem ajudar a gerar a abundância individual,

\footnotetext{
11“O objetivo, seja do desenvolvimento humano, seja dos projetos de redução de pobreza deve ser expandir a capacidade das pessoas de gozar de tudo aquilo que, por si mesmo, tem valor. E o acesso aos recursos dos quais um indivíduo tem necessidade deve ser em função deste objetivo". (Tradução livre dos autores). E continua: "Lo stesso acesso alle risorse di cui un individuo ha necessità deve essere in funzione di quello scopo. La nozione di capacità é dovuta a Amartya Sen che, su di essa, ha costruito un nuovo approccio ala teoria dello sviluppo".
} 
além de recursos públicos para os serviços sociais. Liberdades de diferentes tipos podem fortalecer umas às outras. (SEN, 2000, p. 26)

Nessa mesma linha de raciocínio, Alves et all (2018), explana que:

\begin{abstract}
Mediante empreendimentos individuais e coletivos, o desenvolvimento pretende garantir as condições necessárias à realização pessoal e manifestação das potencialidades, por isso tem na inclusão justa um fator fundamental. Promove valores democráticos e assegura plena participação na política, além de ofertar as assistências sociais necessárias pela vida da política pública à população vulnerável e inseri-las ativamente na vida econômica.
\end{abstract}

Convém lembrar que, nas teorias do desenvolvimento humano e do bemestar, o enfoque das capacidades (Capabilities approach) e o enfoque da felicidade (Hapiness approach) são considerados duas formas distintas de entender e avaliar aspectos da pessoa. Ambos criticam a base da teoria econômica convencional, fundada na geração de recursos e riquezas e da utilidade como forma de bem-estar. Ambos são mais amplos, determinando um novo paradigma, "de que os seres humanos são o fim do desenvolvimento e a atividade econômica é apenas um meio para atingir este fim". (BRUNI, 2008, p. 2)

Primeiramente, surgiu o 'enfoque das capacidades' e toda a literatura de Amartya Sen, suas implicações, críticas e avaliações. Em um segundo momento, surgiu o 'enfoque da felicidade', que aparentemente seria um desdobramento, um aprofundamento do enfoque das capacidades, porém, como determina o próprio Amartya, com diferenças fundamentais.

O enfoque das capacidades propõe uma perspectiva mais rica para a avaliação das liberdades e do bem-estar de cada indivíduo, sendo mais objetiva na forma de avaliação dos critérios para o desenvolvimento. Sen (2011, p. 305) anota também que:

[...] há um contraste entre felicidade e capacidades como ingredientes informacionais básicos de uma teoria da justiça, pois a felicidade não gera obrigações e deveres da forma como a capacidade inevitavelmente gera, se admitirmos o argumento sobre a responsabilidade do poder efetivo. 
Além disso, o enfoque das capacidades é basicamente normativo, ou seja, propõe que a liberdade substancial, os funcionamentos e capacidades se tornem a base informacional para avaliar as necessidades e adequação de ações governamentais e legislativas. Já o enfoque da felicidade analisa o "problema interpretativo do porquê os indivíduos não são capazes de melhorar seu bem-estar, mesmo existindo abundância de recursos materiais e aparente liberdade" (BRUNI, 2008$, p. 5$)^{12}$, tendo um caráter mais geral.

Como é possível perceber, ambos os enfoques partem da mesma origem e inquietação, porém apresentam questões diversas e, consequentemente, assumem caminhos diversos para a solução do problema.

Amartya Sen observa, ainda, a importância do enfoque da felicidade, tanto para o desenvolvimento humano como para o bem-estar e refere-se ao livro "Happiness: lessons from a new Science", de Richard Layard (2005, p. 307), que afirma: "Há um paradoxo no coração de nossas vidas. A maioria das pessoas quer mais renda e luta por ela. No entanto, à medida que as sociedades ocidentais ficam mais ricas, suas populações não se tornam mais felizes".

Esse enfoque da felicidade teve início com R.A. Easterling (1974) e T. Scitovsky (1976), com a obra "Joyless Economy" e, ao longo dos anos, foram criadas duas escolas de pensamento, tanto na economia como na psicologia: a hedonista, de tradição utilitarista, referida a Epicuro (cf. Kahneman et al., 1999) e a 'Eudaimonica', de tradição aristotélica.

A primeira propõe que os prazeres e as dores devem guiar as decisões de fazer (decision-making) individuais, sendo medidas objetivamente. A segunda, a decisão de fazer (decision-making)é guiada pela avaliação individual do que se considera a "vida boa".

A segunda escola refere-se ao conceito de eudaimonia, de Aristóteles, mais amplo que o conceito comum de felicidade. É um conceito multidimensional e relacionado à própria realidade, não identificada com dinheiro ou prazer, mas com a

\footnotetext{
12 "CA's analysis is basically normative, focusing on the issue of substantive freedoms, using functionings and capabilities to provide the main informational basis for evaluating the necessity and adequacy of policy actions. The HA's analysis stresses instead the interpretative problem of why individuals are not able to use abundance of material resources and freedoms efficaciously for improving their own well-being".
} 
própria natureza social do homem. Para Aristóteles, eudaimonia possui três principais características: a) é um fim em si mesmo; b) é o fim da atividade política; c) é um resultado indireto da prática da virtude.

Assim, a escola eudaimonica da felicidade entende o "bem-estar como uma realização plena do daimon ou verdadeira natureza" e propõe, assim, a associação universal entre o bem-estar e a qualidade dos relacionamentos, como a sociabilidade.

Bruni propõe a categoria dos 'bens relacionais' como próprios da natureza humana e fundamentais para o bem-estar, qualidade de vida e felicidade. De acordo com Martha Nussbaum, "amizade, amor e compromisso político" são os três "bens relacionais" básicos do conceito de sociabilidade de Aristóteles encontrados em "Ética a Nicômaco". (BRUNI, 2008, p. 5)

As características dos bens relacionais encontradas na doutrina são: identidade, reciprocidade, simultaneidade, motivações, origem em fatos, gratidão e bem (BRUNI, 2008, p. 132-133). Com base nessas características é que a felicidade (eudaimonia) é o principal fim do desenvolvimento humano dos países, considerando que os governos e os cidadãos voltados para esse fim estarão também realizando sua natureza.

Para Amartya Sen (1993),

\begin{abstract}
A linha de raciocínio desenvolvida aqui baseia-se na avaliação da mudança social em termos do enriquecimento da vida humana dela resultante. A qualidade da vida humana, contudo, é em si mesma uma questão muito complexa. Referindo-se ao problema da "distribuição política", Aristóteles utilizou extensivamente sua análise do "bem dos seres humanos", na qual esse bem é ligado ao exame que faz das "funções do homem" e da "vida no sentido de atividade". Certamente a teoria aristotélica é muito ambiciosa [...]. Mas o argumento no sentido de se conceber a qualidade da vida em termos de atividades valorizadas e da capacidade de desempenhar essas atividades tem relevância e aplicação muito mais amplas.
\end{abstract}

Nesse sentido, demonstra-se a relação entre capacidades e felicidade, pois a compreensão da felicidade, no sentido aristotélico, reporta à natureza social do homem e indica que a busca e realização dos bens relacionais são um indicador de desenvolvimento humano e de centralidade da pessoa e, também, pauta a finalidade do Estado. 
Portanto, para Amartya Sen, a ideia de capacidades (capabilities) está fundamentada no conceito de liberdade substancial, quer dizer, nas capacidades que uma pessoa possui para ser algo escolhido por ela mesma e de realizar atividades que a ajudem alcançar esse fim. $O$ que as pessoas podem fazer e ser (funcionamentos) e as capacidades de que dispõem (oportunidades de escolher e ter um tipo de vida ou outro) são o cerne da ideia de uma sociedade desenvolvida e mais livre.

Com base nesses conceitos é que a 'promoção das capacidades', expressão utilizada por Amartya Sen, determina a ação do Estado como estratégia para a efetivação do desenvolvimento humano.

\section{CONCLUSÃO}

Procurando tecer uma reflexão sobre o desenvolvimento humano segundo a concepção de Amartya Sen, pode-se afirmar que a expansão das capacidades das pessoas deve ser efetivada pelo Estado para que possam usufruir da liberdade de determinar o que é melhor para si e para a sociedade no qual está inserida.

Diante disso, daquilo que foi exposto na presente pesquisa, pode-se concluir que Amartya Sen defende que as capacidades da pessoa não podem ser enumeradas, por se tratar de uma teoria a ser formada por uma série de combinações definidas por um mecanismo de funcionamento que deve ser considerado pelas próprias pessoas, pela sociedade e pelo Estado.

Toda pessoa tem o direito à promoção de suas capacidades, seja pela elaboração de normas que auxiliem nas escolhas individuais, seja como ação do Estado em favor do exercício da sua liberdade. O ponto fundamental da concepção de capacidade é a relação com a liberdade e a possibilidade de transformação dos hábitos.

Sendo o conceito de desenvolvimento uma expansão das capacidades humanas e, relacionando esse conceito à felicidade, chega-se à ideia de capacidades fundamentadas no conceito de liberdade substancial como ponto central de uma sociedade desenvolvida. Logo, a promoção das capacidades da pessoa deve 
configurar uma meta do Estado quando busca alcançar o bem comum e o desenvolvimento humano.

\section{REFERÊNCIAS}

ALKIRE, Sabina. Valuing Freedoms. Sen's capability approach and poverty reduction. Queen Elizabeth House series in Development Studies. Oxford: Oxford University Press, 2008.

ALVES, José Irivaldo; CUNHA, Belinda Pereira da; SOUSA, John Brehmer de. Desenvolvimento e desenvolvimento sustentável: uma revisão contemporânea para pensar políticas públicas num ambiente de complexidade. In: Revista Jurídica UNICURITIBA, vol. 01, n. 50, Curitiba, 2018, pp. 484-513.

BLACKBURN, Simon. Dicionário Oxford de Filosofia. Trad. Desidério Murcho et al. Rio de Janeiro: Jorge Zahar Editora, 1997.

BOMPIANI. Enciclopedia Filosófica. Vol. 2, Fondazione Centro Studi Filosofici di Gallarate, 2006.

BRASIL. Código Civil brasileiro. São Paulo: Saraiva, 2018.

BRUNI, Luigino; COMIN, Flavio; PUGNO, Maurizio. Capabilities and Hapiness. Oxford: Oxford University Press, 2008.

DINIZ, Maria Helena. Dicionário jurídico. Vol. 1. 2. ed. São Paulo: Saraiva, 2005.

ENCICLOPEDIA DEL DIRITTO. Vol. VI. Italia,Giuffrè editore,1960.

FRANÇA, R. Limongi (Ed.). Enciclopédia Saraiva do direito. 1977.

HOUAISS, Antônio; VILLAR, Mauro de Salles. Dicionário Houaiss da língua portuguesa. Rio de Janeiro: Objetiva, 2009.

LAYARD, Richard. Hapiness: lessons from a new science. Londres: Penguin, 2005.

LITTLE OXFORD ENGLISH DICTIONARY. 19. ed. Oxford: Oxford University Press, 2006.

NERY JUNIOR, Nelson; NERY, Rosa Maria de Andrade. Código Civil Comentado. 7. ed. São Paulo: RT, 2009.

NUSSBAUM, Martha; SEN, Amartya. (comp.) La calidad de vida. Trad. Roberto Ramon Reyes Mazzoni. México: FCE, 1996. 
RAWLS, John. Uma Teoria da Justiça. São Paulo: Martins Fontes, 1997. A obra foi publicada pela primeira vez em 1971.

SEN, Amartya. Commodities and Capabilities. Nova Delhi: Oxford University Press, 1985.

2000.

Desenvolvimento como liberdade. São Paulo: Companhia das Letras,

. Desigualdade Reexaminada. Rio de Janeiro: Record, 2008.

. Estado, reformas e desenvolvimento: o desenvolvimento como expansão de capacidades. In: Revista Lua Nova, n. 28-29. São Paulo, abr. 1993. Disponível em: http://dx.doi.org/10.1590/S0102-64451993000100016. Acesso: 10 jan. 2019.

Equality of what? The Tanner Lecture on Human Values, Stanford University, May. 22, 1979.

. Ideia de Justiça. São Paulo: Companhia das Letras, 2011.

. La calidad de vida. México: FCE, 1996.

1987

. The standard of living. org. G. Hawthorne, Cambridge University Press,

Well-being, Agency and Freedom. The Dewey Lectures 1984". Journal of Philosophy, v.82, abril de 1985, p. 187, 200-201. Press, 1982.

; WILLIANS, B. Utilitarism and Beyond. Cambridge: Cambridge University 